\title{
PhD supervisors and faculty members might help to avoid burnout as well as enhance engagement and organisational citizenship behaviour (OCB) among PhD students.
}

\author{
Patricio Saavedra $^{1 * *}$, Evangelos Ntontis ${ }^{1,2}$, \& Arabella Kyprianides ${ }^{1}$. \\ 1. School of Psychology, University of Sussex, UK. \\ 2. School of Psychology, Politics and Sociology, Canterbury Christ Church University, \\ UK.
}

December 2018.

There has been increased interest in the wellbeing and mental health of postgraduate students in light of the recent portrayal of the academic career as overworked and isolated. Research points to $\mathrm{PhD}$ students as being particularly at risk, yet the factors that contribute to $\mathrm{PhD}$ students' compromised wellbeing are unclear. In this study $(N=392)$, we combine the social cure approach in social psychology with advances in organizational psychology to investigate potential predictors of work-related wellbeing and organisational citizenship behaviour (OCB) among PhD students in the UK. In particular, we explore the relationships between social support, willingness to support others, clarity of role, group belonging, engagement, and burnout using structural equation modelling (SEM). Our results point to the importance of support provided by both the supervisor and faculty members in helping to avoid burnout and enhance engagement among students. We also found that students' identification with supervisors and faculty members together with clarity of role are positively associated with students' work-related well-being. Moreover, although particular processes differ for early vs. late stage PhD students, our findings suggest that support from faculty members is a key predictor of intentions to perform OCB. Thus, received support is positively related to performing OCB both directly and indirectly via a sense of identification with faculty members. We discuss the implications of our findings in relation to policies aiming at improving the well-being of PhD students.

Keywords: $\mathrm{PhD}$ students, social support, burnout, engagement, social identity, organisational citizenship behaviour.

\footnotetext{
** Correspondence should be addressed to Patricio Saavedra, School of Psychology, University of Sussex, United Kingdom (email: ps356@sussex.ac.uk).
}

DOI: http://dx.doi.org/10.20919/Psych(2019).001 


\section{Introduction}

\section{Background}

PhD students' well-being has been a concern during the last years, especially in light of UK academic staff reports of high levels of anxiety and stress related to their jobs. A growing number of academics holding a position in UK universities are currently suffering from high workloads, an increasing number of working hours (even during the weekend), and a poor family-work balance (Bothwell, 2018; University and College Union (UCU), 2016). In addition to this, the current academic environment promotes competition (instead of collaboration) with others for grants and publications, while has increasing demands and expectations from students. The above, in conjunction with the social isolation that academics frequently experience within academia, contribute to impoverishing the everyday lives of academic staff and doctoral students.

Being enrolled in a PhD program can be a unique experience, and often not a good one. Previous research has found that $\mathrm{PhD}$ students deal with multiple and complex tasks within a context of limited time and high pressure, and face emotional costs associated with a process in which they struggle between feeling inspired and emotionally exhausted (Stubb, Pyhältö, \& Lonka, 2011). Consequently, recent reports have shown that, in general, doctoral students' well-being might be at risk considering a lot of them suffer from anxiety, stress, and depression because of increasing pressure entailed in their programs (Evans, Bira, Gastelum, Weiss, \& Vanderford, 2018; Woolston, 2018). Doctoral students also appear to have higher chances of developing any other mental health issue in comparison to the general population (Levecque, Anseel, De Beuckelaer, van der Heyden, \& Gisle, 2017). In addition, in these reports, job demands (e.g., workload), the feeling of control over their own job, the role of the supervisor (i.e., time and quality of contact), and the support that students perceive to be receiving from their academic community, have been posited as common antecedents for $\mathrm{PhD}$ students' wellbeing.

Stress, then, might be one of the most important threats for PhD students' well-being. However, just a few studies have explored the presence or the antecedents of burnout in the doctoral student population (e.g., Galdino, Martins, Fernandez Lourenço Haddad, Cruz Robazzi, \& Birolim, 2016; Peltonen, Vekkaila, Rautio, Haverinen, \& Pyhältö, 2017; Rigg, Day, \& Adler, 2013). We can understand burnout as a reaction to chronic stress related to work that provokes 
people to feel constantly exhausted, to develop a sense of callousness or cynicism to other people and their work, as well as to feel less professionally efficacious (Maslach \& Leiter, 2008). In addition, despite burnout being initially conceptualised as a condition that could affect only those people whose job involved interpersonal contact (e.g., healthcare workers), a wide body of research has explored burnout, its antecedents and consequences, on workers from different professions and organisations, finding it to be just as applicable to different work contexts (Maslach, 2003; see Maslach \& Schaufeli, 1993 for a review; see Schaufeli \& Buunk, 2004 for a review). Although burnout can be partially explained by personal traits, it comes about via increasing job demands and workloads, and can be tackled using the right resources (e.g. receiving feedback and support) (Schaufeli \& Bakker, 2004a). Moreover, recent advances have identified that effective leadership by supervisors (Sijbon, Lang, \& Anseel, 2018; Steffens, Yang, Jetten, Haslam, \& Lipponen, 2018), and the support of others (i.e., colleagues), might also play a key role in the manifestation of burnout and its impact on individuals (e.g., willingness to turnover) and organisations.

Another factor that might be related to $\mathrm{PhD}$ students' well-being is the level of engagement they have with their programs. In fact, engagement has been defined as the positive opposite of burnout (González-Romá, Schaufeli, Bakker, \& Lloret, 2006). Thus, engagement has been characterised as a positive state of mind in the workplace, in which people are willing to invest a lot of effort in their tasks (vigor), feel inspired and enthusiastic (dedication), and be fully concentrated on what they are doing (absorption) (Schaufeli \& Bakker, 2004b). Regarding the antecedents of engagement, previous work has concluded that $48 \%$ of people's work engagement can be explained by personal traits (Young, Glerum, Wang, \& Joseph, 2018), and the remaining causes can be explained by contextual factors such as job resources (Macey \& Schneider, 2008). Nevertheless, unlike burnout, the relation between engagement and job demands is not as clear. In line with this, a recent study has pointed out that engagement might be positively related to those job demands that represent a challenge for the individual, but negatively related to those job demands that people see to be a hindrance to their job (Crawford, LePine, \& Rich, 2010).

\section{The present study}

In this study, we try to identify the factors that can be associated with the avoidance of burnout and the promotion of engagement among PhD students. To achieve this, we combine advances in organisational psychology with the social cure approach in social psychology. The latter 
corresponds to a theoretical and practical psychological framework whereby group identification (e.g., with faculty members) plays a key role in the provision of support for the members of these groups; what in turn might become the main resource that promotes people's health and successful coping with stressful situations (Haslam, Jetten, Cruwys, Dingle, \& Haslam, 2018; Haslam, O'Brien, Jetten, Vormedal, \& Penna, 2005; Jetten, Haslam, \& Haslam, 2012). Through our work with $\mathrm{PhD}$ students we expect to expand the scope of the social cure approach in two ways. First, despite the social cure proposition that group identification precedes both the objective provision and the perceptions of being supported by others (e.g. Haslam et al., 2018), we suspect that this relationship might also work in the opposite way (such that perceived support leads to identification with the group) in contexts (such as academia) where people's activities are highly independent (even isolated) and their job demands are particularly high. In other words, we propose that when people perceive they are supported by others, they might identify with them by developing a sense that they belong to the same group (e.g., 'I'm in the same group with the other faculty members'). Second, we aim to provide empirical evidence for Haslam's (2004) proposition that social identity (e.g., identification with the academic community) might underpin acts of self-sacrifice such as Organisational Citizenship behaviour (OCB) (i.e., carrying out extra-role behaviours like helping colleagues without being asked) (see a review of OCB in a later section in this report).

Our aims in the present study were the following:

- To explore the relationship between the support provided by PhD supervisors and other faculty members and the promotion of students' work-related wellbeing (i.e., prevention of burnout and engagement with the $\mathrm{PhD}$ program).

- To investigate whether perceived progress in the program (e.g., successfully completing the research project) helps to decrease the risk of students suffering from burnout, while promoting students' dedication and motivation with tasks they need to accomplish.

- To investigate whether group belonging (e.g., in the academic community) and perceived support by the associated group members might help to promote OCB, understood as the willingness of supporting others in the academic context. 


\section{Method}

We collected our data via an online survey that we distributed on social media (Facebook and Twitter). We also shared the survey link with faculty members known to us from universities across the UK. The survey link was also hosted on a webpage set up by the Doctoral School of the University of Sussex ${ }^{\dagger}$ to support the data collection process.

We used an online questionnaire (see Supplementary Material) with a large set of scales measuring different psychological and organisational factors that might affect the wellbeing of PhD students. However, in this report, we only describe the variables used in our final analysis.

\section{Measures}

Support. We measured practical support provided by the supervisor using four items. Three items were adapted from Norris and Kaniasty (1996) (e.g., 'My supervisor helps me to do things that need to be done'), and one was our own elaboration. We also adapted 4 items from Norris and Kaniasty (1996) to assess practical support provided by faculty members (e.g., 'I receive information from members of my faculty which help me to understand a situation'). Participants responded to these items on a 5-point Likert-type scale ranging from 1 (Strongly disagree) to 5 (Strongly agree).

Willingness to support others. We also included 3 items that measure participants' willingness to support other $\mathrm{PhD}$ students (e.g., 'Other PhD students can count on me to meet their needs if things go wrong') adapted from Alnabulsi and Drury (2014) and Ntontis (2018).

Clarity of role. To measure student's clarity of role, we included three items adapted from the role ambiguity scale developed by Breaugh and Colihan (1994) (e.g., 'I'm very sure about how to do my work'). Although these items were originally developed to measure the ambiguity of workers' roles, we used positive worded items and thus used the label "clarity”, in line with other scales created for the same purpose (see Bowling et al., 2017 for a review).

\footnotetext{
${ }^{+}$http://www.sussex.ac.uk/internal/doctoralschool/wellbeing/psychosocial
} 
Identification. Student's identification with their supervisor and faculty members was measured using adaptations of the single-item measure for social identification developed by Postmes, Haslam, and Jans (2013) (e.g., 'I identify with other people from my faculty').

Engagement. Engagement scores were calculated using UWES-3 (An ultra-short measure for work engagement; Schaufeli, Shimazu, Hakanen, Salanova, \& De Wittie, 2017). This instrument comprises three items that we adapted for the context of $\mathrm{PhD}$ students' engagement (e.g., 'I am immersed in my $P h D$ '). We kept the original 7-point scale where 0 means "never” and 6 "always” or "every day”.

Burnout. Burnout was measured using an adapted version of the nine-item scale developed by Haslam \& Reicher (2006) (e.g., 'I feel I am working too hard for my PhD') where participants indicate their agreement with each sentence (1 "Don't agree at all” to 7 “Completely agree”).

\section{Participant information}

Our final sample comprises of $392 \mathrm{PhD}$ students. Although $411 \mathrm{PhD}$ students met our ad-hoc criteria of completing more than $50 \%$ of the survey, cases that had multiple missing values were excluded from our analyses, leaving us with a total sample size of 392. Most participants are women (76.28\%), British (66\%), young or middle-aged adults ( $M=33.3 S D=9.1$ ), and registered as full-time students (81\%). The vast majority of our participants are enrolled in a program related to social sciences (65.56\%), whilst programs associated with sciences and technology (16.58\%), health sciences (8.93\%), and humanities (8.93\%), are underrepresented. $52 \%$ of our participants are early stage $\mathrm{PhD}$ students ( $1^{\text {st }}$ and $2^{\text {nd }}$ Year), while the rest reported being in a later stage ( $42 \%$ were in the $3^{\text {rd }}$ or $4^{\text {th }}$ year of their program, and $6 \%$ were in their $5^{\text {th }}$ or $6^{\text {th }}$ year).

Considering that $\mathrm{UK} \mathrm{PhD}$ programs are research-based, the supervision process can be a key factor in the students' progress. In our study, $72.1 \%$ of students declared that they have one or two supervisors with whom they have a good or very good relationship, despite $56.4 \%$ of respondents meeting their main supervisor just once per month (the minimum required in UK universities). Regarding the working hours, approximately $80 \%$ of students declared dedicating 8 or less hours per day to their PhD. Interestingly, even though most of the participants reported being registered as full-time PhD students, $46.7 \%$ of them said they have another job in which 
they commit an average of 4 hours per day. In addition, 30\% of the participants declared that they need to spare time to take care of others (child, aging or ill relatives).

\section{Results}

Our results section is the report is broken down into three parts. First, we report descriptive statistics relating to our key variables of interest. Second, we report results on a model that predicts burnout and engagement among PhD students. Third, we report results on a model that predicts organisational citizenship behaviour (OCB) among PhD students. In this latter case we compare early stage $\mathrm{PhD}$ students to those in a later stage of their program.

\section{Descriptive statistics}

With respect to engagement (see Figure 1), we can say its distribution is moderately negatively asymmetrical (Skewness $=-0.67, M=3.41, S D=1.58$ ). Thus PhD students have a tendency to feel immersed and enthusiastic with their work, whilst they may be willing to invest a lot of effort in their program regardless of the difficulties they might face. Even though the literature has highlighted some potential risks of high engagement to the dedication of time to family members (see Halbesleben, Harvey, \& Bolino, 2009), we think universities should implement active policies to enhance engagement among doctoral students considering it might benefit individuals (e.g., improving academic performance or satisfaction with the program), and the organisation itself (e.g., incrementing organisational commitment and reducing students' intentions to quit from their programs).

Another topic of interest concerned the level of burnout reported by PhD students. We found that the distribution of burnout (see Figure 1) deserves some special attention considering it is too close to normal distribution (Skewness $=0.16$, Kurtosis $=2.71, M=3.58, S D=0.92$ ). This means that most of the doctoral students report some level of chronic stress related to their research program, while just a few have experienced either very low or high levels of burnout. However, ideally, burnout scores should present an asymmetrical distribution where the lower end includes the vast majority of the scores while medium-high scores should be the exceptions. 

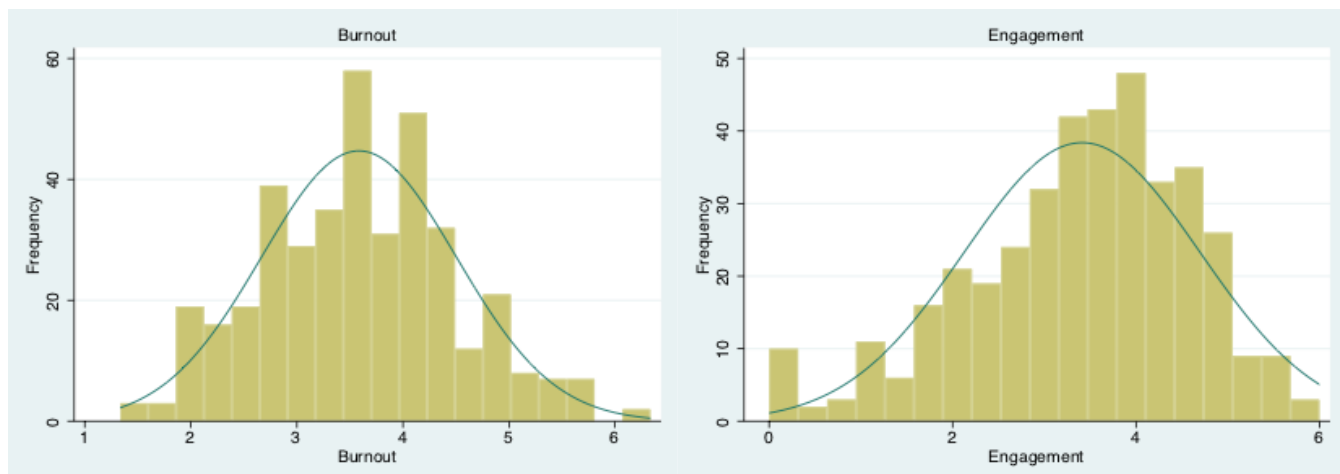

Figure 1. Distribution scores for burnout and engagement amongst PhD students.

In addition to the results described above, we explored whether the levels of both engagement and burnout were the same for students in different years of their $\mathrm{PhD}$. With regard to students' engagement, we found statistically significant differences between first year students and those in the third year of their program. Furthermore, our analyses also revealed that students in their sixth $\mathrm{PhD}$ year seem less motivated and less focused on their research projects compared to students who are just starting their programs. Even though only the mentioned contrasts showed statistically significant differences, we can see there is a general tendency for students at later stages of their PhD (except for year 4) to report lower levels of satisfaction.

In relation to the reported levels of burnout, our analyses demonstrated that first year students feel significantly less stress compared to students in the third, fourth, and sixth year of the program, respectively. Although the differences between students from other years (e.g., first and third year) were not statistically significant, we want to highlight that a general tendency might exist for students to report higher levels of stress and exhaustion in relation to their research projects over the passing of time (see Figure 2).

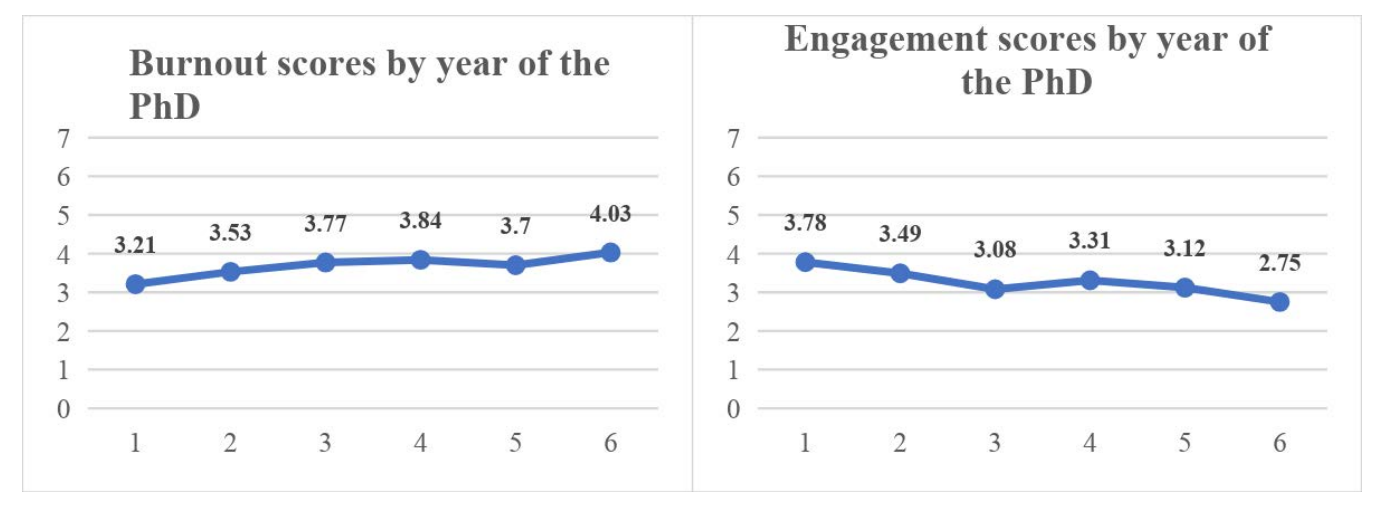

Figure 2. Burnout and engagement scores by year of the PhD. 
In summary, we may say that students in the first stages of their programs seem more enthusiastic and inspired by their work, whilst those in their final years might feel more exhausted and stressed due to some specific work demands such as conducting the research, writing up their thesis, or submitting papers/chapters to scientific journals. In addition, we want to clarify that these results must be interpreted carefully, considering we are comparing independent groups of students (by year) and not the same students (or the hypothetical changes they might suffer in relation to engagement or burnout) over time. For this, a longitudinal study where the students can be followed-up in different periods of time is required.

Regarding identification with the main supervisor and with faculty members, our analysis shows that almost $60 \%$ of students identified or strongly identified with their main supervisor(s); while around 56\% reported identifying with colleagues and academic staff. With respect to the practical support received from these two groups, students reported having received a lot of support from their supervisors to accomplish the work demands associated with a doctoral program (Skewness $=-1.00, M=3.83, S D=1.04$ ), whilst it seems this tendency is not so strong for the support received from faculty members (Skewness $=-0.52, M=3.38$, $S D=1.00)$. An issue worth mentioning here is that our measure of support received from faculty members does not make any distinction between academic staff, professional staff, and other $\mathrm{PhD}$ students. As such, the results reported in relation to this variable should be interpreted carefully, considering that participants might have identified and mixed diverse sources of reference when they evaluated the items.

Regarding students' clarity of role (knowledge of their obligations and duties of the program they are enrolled in), we found that, despite that the average of the obtained scores is above the mid-point of the scale (Skewness $=-0.09, M=4.09, S D=1.4$ ), there are heterogeneous opinions. Some students reported that they clearly recognize their role, responsibilities and aims, while others reported that they are not very sure about how to conduct their research projects properly. Although some researchers have pointed out that the extent to which people feel they know how to do their jobs is negatively related to burnout (Olivares-Fernández, GilMonte, Mena, Jélvez-Wilke, \& Figueiredo-Ferraz, 2014; Tunc \& Ozen Kutanis, 2009), and therefore high levels of clarity of role should be desirable, we think the current distribution of the scores in our sample might not be a matter of concern when taking into account that uncertainty could be considered an intrinsic part of scientific work. Conversely, we also think that university groups and $\mathrm{PhD}$ supervisors might play a crucial role in helping students not 
lose confidence in their academic skills and keep track of their roles and goals at different stages of their programs (though we found that there were large discrepancies among students across different years of their programs).

\section{Model 1: Predicting student burnout and engagement with their program}

We used structural equation modelling (SEM) to investigate the predictors of burnout and engagement levels in our sample, whilst controlling for age, gender, number of hours dedicated to the research project per day, and the year of the $\mathrm{PhD}$ (see Figure 3). Moreover, in Table 1, we present the zero-order correlations between the variables included in the predictive model.

Table 1. Correlations between the key variables.

\begin{tabular}{lccccccccc}
\hline Variables & 1 & 2 & 3 & 4 & 5 & 6 & 7 & 8 & 9 \\
\hline 1. Engagement & -- & & & & & & & \\
2. Clarity of role & $.43^{* * *}$ & -- & & & & & & \\
3. Burnout & $-.60^{* * *}$ & $-.38^{* * *}$ & -- & & & & & & \\
4. Support (supervisor) & $.29^{* * *}$ & $.22^{* * *}$ & $-.39^{* * *}$ & -- & & & & \\
5. Identification (supervisor) & $.29^{* * *}$ & $.19^{* *}$ & $-.29^{* * *}$ & $.64^{* * *}$ & -- & & & \\
6. Support (faculty members) & $.22^{* * *}$ & $.24^{* * *}$ & $-.30^{* * *}$ & $.28^{* * *}$ & $.19^{* *}$ & -- & & \\
7. Identification (faculty members) & $.16^{* * *}$ & $.14^{*}$ & $-.19^{* *}$ & $.22^{* * *}$ & $.21^{*}$ & $.60^{* * *}$ & -- & & \\
8. Age & .13 & .04 & $-.12^{*}$ & .03 & .08 & $-.14^{* *}$ & -.07 & -- \\
9. Hours dedicated to the PhD & .02 & .06 & .08 & -.04 & -.12 & .05 & .06 & $-.29^{* * *}$ & -- \\
\hline
\end{tabular}

${ }^{*} p<.05 . * * p<.01 . * * * p<.001$.

Our proposed model explained 52\% of the variance in burnout, and $36 \%$ of the variance in engagement with the PhD program, which verifies the high predictive power of our model. Our most important findings are a) that the practical support given by both the supervisor and faculty members may help to decrease the risk of burnout among students; and b) that $\mathrm{PhD}$ supervisors might play a key role in keeping students motivated to progress in their programs by providing them with practical support and guidance, as well as by acting as role models, and by fostering a good relationship (to promote identification). 
Our results are in line with previous literature that has focused on organisational environments where resources provided at the interpersonal level (i.e., support from colleagues), as well as at the organisational level (i.e., support from supervisor), help to decrease levels of burnout among workers, but more importantly to increase people's motivation and dedication associated with their jobs (Schaufeli \& Bakker, 2004). Moreover, our findings highlight the role of leaders (in this case of $\mathrm{PhD}$ supervisors) in acting as role models who create a sense of belonging that may contribute to the promotion of students' engagement with the tasks related to their projects. This partially confirms results from previous research that has shown that identification with the leader both increases workers' motivation and dedication to their tasks, and reduces the chances of suffering burnout at work (Steffens et al., 2018). Therefore, we think more research is needed in the context of Higher Education (at postgraduate level) to clarify the role of academic supervisors (i.e., as role models and managers) in reducing or increasing the chances that their students present symptoms of burnout during the $\mathrm{PhD}$ program.

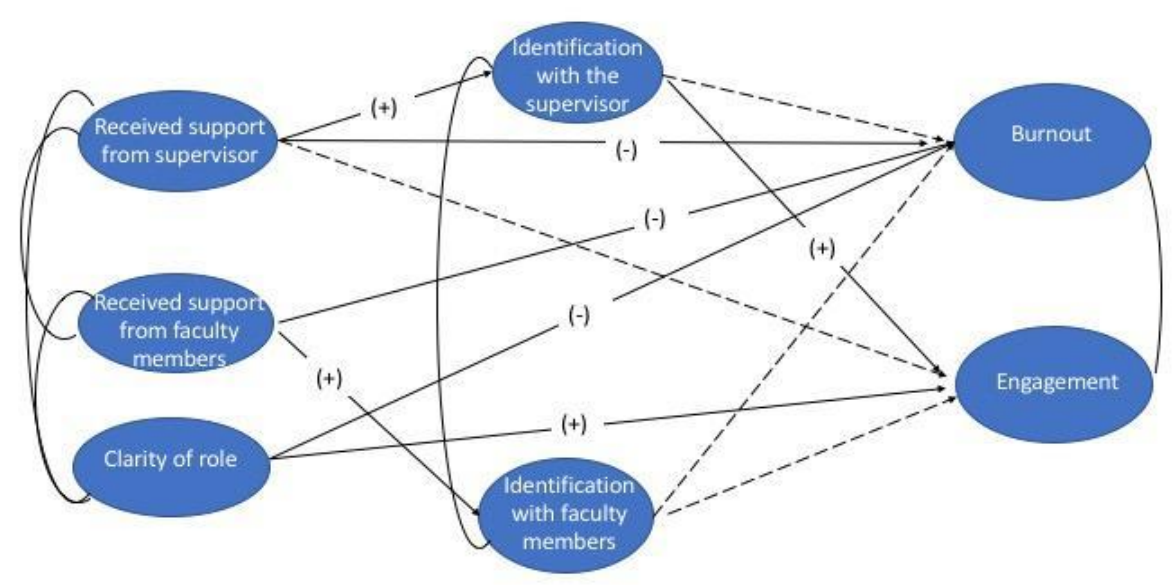

Figure 3. SEM model predicting burnout and engagement among PhD students.

Although the social cure approach has argued that the sense of belonging (i.e. identification) to a group (e.g., faculty) might be a protective factor against burnout or a booster for engagement (Haslam et al. 2018), we were not able to show that identification had an impact on burnout nor engagement. Therefore, faculty members' best bet to reduce students' burnout, and increase their engagement, may be through the provision of direct support as described above. It is however necessary to point out that effects of groups on individuals might be beneficial (e.g., in the case that they boost engagement) or harmful (e.g. in the case that they lead to increased burnout symptoms) depending on the specific characteristics of these groups 
and their dynamics (Haslam, Reicher, \& Levine, 2012). One reason for these unexpected results, then, is that participants came from different universities, faculties, and research groups. Another reason, related to this, is that students might have identified diverse groups of people as “faculty members” (e.g., academic staff, professional staff, or colleagues) as a group of reference.

In addition, in our student sample we replicated previous findings from the literature on the importance of clarity of role in reducing the risk of burnout (Olivares-Fernández et al., 2014; Tunc \& Ozen Kutanis, 2009), and increasing the engagement with work tasks (Curran \& Prottas, 2017; Lin, Shin, \& Baek, 2017). This means that the more students feel they know both the proper procedures, and the best way to conduct their research projects, the less likely it is that they show signs of stress associated with their PhD program. Conversely, the extent to which students feel confident about how to conduct their research might be directly associated with their engagement with the program.

\section{Model 2: Predicting student organisational citizenship behaviour (OCB)}

A common area of interest in organisational psychology is Organisational Citizenship Behaviour (OCB). OCB is a behavioural consequence of engagement with work. Although there is not a unique definition of OCB, some authors (see Organ, 2018 for a review; Smith, Organ, \& Near, 1983; Van Dyne, Graham, \& Dienesch, 1994) have stated that it is a concept which spans along multiple dimensions (e.g., loyalty, altruism, and compliance) and behaviours (e.g., helping others with various tasks, not wasting time, being punctual). A common feature within these definitions is that OCB is implicit and thus based on conventional relationships and cooperation within organisations, rather than on an explicit contract (Van Dyne et al., 1994). Therefore, we can define OCB as those actions carried out by workers (in this case $\mathrm{PhD}$ students) beyond their formal duties (i.e., attending courses or supervision meetings, and working on their own research projects) that might benefit the organisation as whole (e.g., by increasing objective productivity or improving organisational climate) and facilitate the work of supervisors and colleagues (i.e., giving feedback or supporting others to accomplish specific tasks). However, it is necessary to stress that despite OCB being highly beneficial for organisations and their members, the implementation of such behaviours implies a self-sacrifice (i.e., the willingness to "go the extra mile") by some members on behalf of common goals (at organisational or department level) or other individuals within an 
organisation. Due to these self-sacrifices, OCB might have both positive (e.g., feel more energised at the end of the day) (Lam, Wam, \& Roussin, 2016) and negative (e.g., interference with family time) (Halbesleben et al., 2009) consequences. Those who engage in OCB should therefore be analysed carefully by each organisation (including universities).

With regard to the evaluation of OCB, it is generally assessed through actual behaviours carried out by workers. However, we consider our measure of "willingness to provide support to others" as a proxy of OCB (based on self-reported intentions), taking into account that one of its most representative dimensions refers to behaviours directly aimed at helping other people in a work context (e.g., to solve specific tasks) even though the providers of support are doing so outside of their specific roles. Moreover, previous literature has identified that OCB might depend on personal traits (Organ, 2018) as well as environmental aspects like leadership (Ilies, Nahrgang \& Morgeson, 2007; Smith et al, 1983), team cohesion (Pucheu, in press), and role stressors including conflict and ambiguity of role (understood as the opposite to clarity of role) (Curran \& Prottas, 2017; Lee, Shin, \& Baek, 2017; Mañas et al., 2018)

Having defined OCB, in this section we present the results of an exploratory analysis where we divided our sample into two groups, the early $\left(1^{\text {st }}\right.$ and $2^{\text {nd }}$ year $\mathrm{PhD}$ students $)$ and late stage students ( $3^{\text {rd }}$ year+ $\mathrm{PhD}$ students). Our aim was to compare the role of support and identification as predictors of PhD students' intentions to perform OCB according to their years of enrolment in the program.

In a first step, we found that students in our sample were very keen to listen to others students' PhD-related problems and to provide support to their colleagues. Even though there were just marginal differences for the intention to perform OCB according to the stage of the PhD (Early stage $M=4.42, S D=0.60$; Late stage $M=4.29, S D=0.72 ; t(390)=1.92, p=.054)$, in a subsequent step we decided to perform the same analysis and further explore whether the influence of these variables on the willingness to support others differed between early and late stage $\mathrm{PhD}$ students. Our comparison demonstrated that early stage $\mathrm{PhD}$ students reported receiving greater support from their supervisor (Early stage: $M=4.02, S D=0.94$; Late stage: $M=3.63, S D=1.11 ; t(390)=3.78, p<.001)$ and faculty members (Early stage: $M=3.5, S D$ $=0.97$; Late stage: $M=3.26, S D=1.03$; $t(390)=2.30, p=.02$ ) compared to colleagues in the final years of the program. We reasoned that this difference might exist because some universities or faculties implement policies and activities specifically aimed at helping new 
students to adapt to the program and the academic environment. Students in their final years, conversely, might be more focused on tasks that need to be done individually and that require less supervision (e.g. writing up chapters of their thesis). In the case of identification, we found that early stage students identified more with both their supervisors (Early stage: $M=3.66, S D$ $=1.15$; Late stage: $M=3.29, S D=1.28 ; t(390)=2.98, p=.003$ ) and faculty members (Early stage: $M=3.46, S D=1.05$; Late stage: $M=3.22, S D=1.22 ; t(390)=2.10, p=.03$ ) compared to students in the last years of their programs.

Regarding our predictive model, we included the frequency of meeting with the main supervisor as a new predictor of willingness to support other students. Although meetings can be considered a formal requirement for some types of jobs (such as for $\mathrm{PhD}$ students), workers (in our case PhD students) might also look at these activities as OCB carried out by the supervisor on behalf of them which might also increase the likelihood that workers (or students) provide support to others within the organisation (Smith et al., 1983). We used SEM to evaluate our model which controlled for age, gender, number of hours dedicated to the PhD program per day, and background of the student (British vs international students). In Table 2, we present the zero-order correlations between the variables included in our predictive model.

Table 2. Correlations between key variables.

\begin{tabular}{|c|c|c|c|c|c|c|c|c|}
\hline Variables & 1 & 2 & 3 & 4 & 5 & 6 & 7 & 8 \\
\hline 1. Willingness to support others & -- & & & & & & & \\
\hline 2. Clarity of role & $.11^{*}$ & -- & & & & & & \\
\hline 3. Support (supervisor) & $.12 *$ & $.22 * * *$ & -- & & & & & \\
\hline 4. Identification (supervisor) & $.13^{* *}$ & $.19^{* *}$ & $.64 * * *$ & -- & & & & \\
\hline $\begin{array}{l}\text { 5. Frequency of meeting with the } \\
\text { supervisor }\end{array}$ & .08 & -.01 & $.21 * * *$ & .05 & -- & & & \\
\hline 6. Support (faculty) & $.33 * * *$ & $.24 * * *$ & $.28 * * *$ & $.19 * *$ & $.13^{* *}$ & -- & & \\
\hline 7. Identification (faculty) & $.38 * * *$ & $.14^{* *}$ & $.22 * * *$ & $.21^{* * *}$ & $.10^{*}$ & $.60 * * *$ & -- & \\
\hline 8. Age & $-.21 * *$ & .04 & .03 & .08 & $-.25 * * *$ & $-.14^{* *}$ & -.07 & -- \\
\hline 9. Hours dedicated to the $\mathrm{PhD}$ & $.14^{*}$ & .06 & -.04 & $-.12 *$ & $.24 * * *$ & .05 & .06 & $-.29 * * *$ \\
\hline
\end{tabular}
${ }^{*} p<.05 .{ }^{* *} p<.01 .{ }^{* * *} p<.001$. 
The calculated model explained 30\% of the variance in OCB for early stage PhD students, and $24 \%$ of the variance in OCB for late stage PhD students. In Figure 4, we differentiate the results for all students (black arrows), only early stage $\mathrm{PhD}$ students (light blue arrows), and late stage PhD students (red arrows).

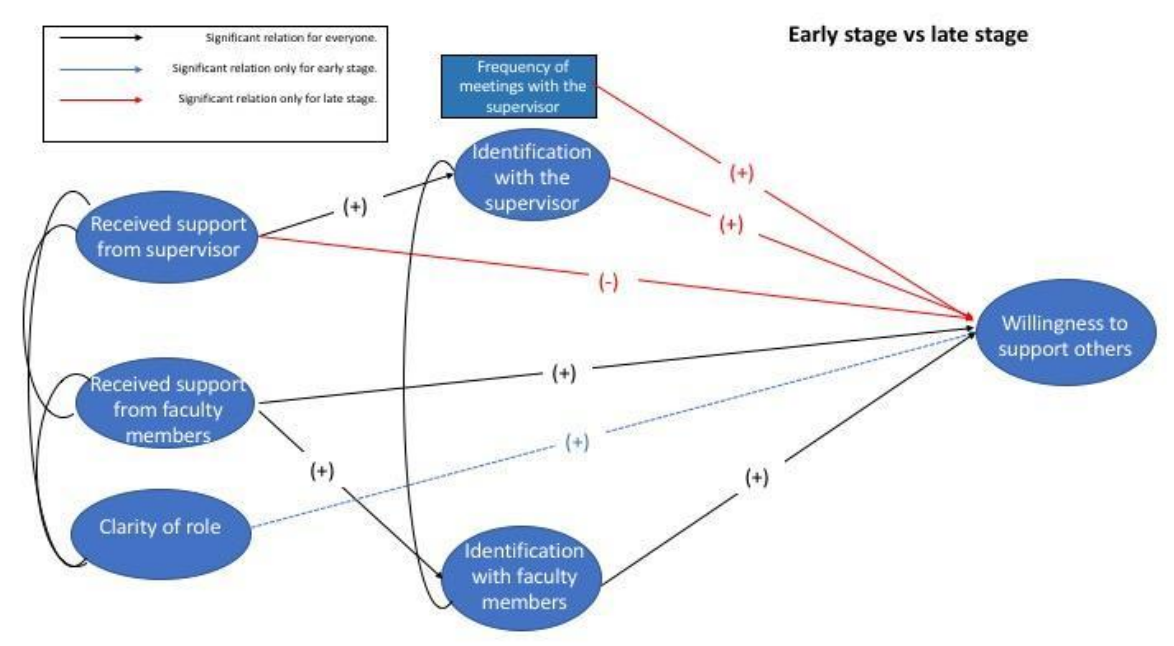

Figure 4. Model predicting OCB among PhD students.

Our analysis shows that the key factor that can affect the intention to perform OCB among PhD students is the received support from faculty members. Support from faculty members affected OCB both directly and indirectly via a sense of identification with faculty members. Our analysis also shows that supervisors play a role in promoting OCB - but only for late stage $\mathrm{PhD}$ students. Thus, more frequent supervisor meetings might increase students' willingness to support other PhD students. We suspect that this observation occurs because students recognize the extra effort made by supervisors as an act to help them, rather than construing this supportive behaviour as simply a formal obligation. We also found that higher identification with the supervisor increased students' willingness to support their colleagues. However, unlike the support received from faculty members, the practical support provided by the $\mathrm{PhD}$ supervisor was negatively correlated with the willingness to help other members of the student community. We consider this an unexpected result that needs further exploration because of the support given by the supervisor should act as a resource that would help to promote positive feelings and behaviours among students (as was demonstrated in the model predicting engagement).

Finally, despite our expectation that more years of experience (in the $\mathrm{PhD}$ ) might lead people to feel more confident about their own expertise in a specific field and increase willingness to support colleagues, our results demonstrated the opposite. We found that students in their early 
years are more willing to perform OCB and have better clarity of their roles compared to students in later stages of their studies. Although we don't have a clear answer for this yet, we think some specific situations (e.g., the intense workload they face and the more isolated tasks they have to carry out at the end of their studies) might be associated with the interference of this relation for $\mathrm{PhD}$ students in their last stage.

\section{Practical implications}

The following is a brief list of the implications our research might have to improve the wellbeing of PhD students:

a. Supervisors play a key role in promoting students' engagement with their $\mathrm{PhD}$ programs by providing them support, but also by being a positive role model for them. The latter also might encourage students to be more willing to spend time helping colleagues in need. However, the importance of the supervisor's role in the process mentioned above should be considered carefully because of two reasons. First, recent literature has stressed that those who act as a role model in their organisations can suffer from emotional exhaustion as a consequence of the demands associated with it (Lin, Scott, \& Matta, 2018). Second, academic staff in the UK have reported suffering from heavy workloads and excess of working hours (Bothwell, 2018; University and College Union (UCU), 2016). Hence, we think it may be counter-productive to expect PhD supervisors to put more efforts towards helping more of their students or being a good role model, without modifying their current workloads and responsibilities within their faculties.

b. Faculty members might have the power to facilitate the conditions for a virtuous circle of cooperation (based on OCB) among PhD students through the provision of practical support (e.g., advice, information) and the creation of a sense of belonging ("us") between the members of an academic community. The latter is in line with an extensive body of literature on the social cure, which shows that identification with a group might promote support between their members (Haslam et al., 2018).

c. As indicated previously, feelings of doing well in their program might encourage $\mathrm{PhD}$ students in an early stage to help their colleagues (performing OCB). Therefore, we 
think universities and faculties should promote environments with clear, secure, and established rules that encourage students to feel more confident about their own skills and knowledge.

d. Even though we do encourage research that helps to better understand well-being among $\mathrm{PhD}$ students, and point to burnout and engagement as important parts of the story, we want to highlight that the policies universities may implement to address these issues need to acknowledge the potential negative effects of being too engaged with work. There is a real risk that being too dedicated and motivated to work, can result in burnout, while it might also create an interference with other dimensions of people' life (Halbesleben et al., 2009).

e. As explained earlier, indices of work-related well-being, like engagement and (the absence of) burnout, might be explained by both environmental (where organisations can intervene directly) and individual factors. Hence, it is important that efforts to improve PhD students' well-being operate at the individual level as well; and this could take the form of counselling services or student assistance through life centres on campus, both of which would actively and widely promote the wellbeing of postgraduate students.

\section{Limitations of this study}

a. Sample size and representativeness: One of the most important limitations of this study is its small sample size in comparison with the total number of doctoral students in the UK (100,085 in 2016-2017 according to Higher Education Statistics Agency, HESA). This, and the fact that $65 \%$ of our participants were students from the Social Sciences, prevents generalisation of our results to all doctoral students across the UK.

b. Cross-sectional study: Considering we used a cross-sectional design, neither causality can be assumed, nor changes over time for the variables of interest (i.e., levels of burnout and engagement). 
c. Differentiation of "faculty members": The items we used to measure support provided by faculty members did not differentiate between the actors in a university context (e.g., academic staff, professional staff, and colleagues).

d. Identification measurement: We measured identification with the supervisor using a general approach (i.e., “I identify with my supervisor”), without making any reference to the specific type of leadership mentioned in the literature - especially those built-in the social cure approach, such as the entrepreneur leadership type (Steffens et al, 2018) or the more inclusive identity leadership type (van Dick et al., 2018).

e. Absence of measures to assess PhD students' job demands and psychosocial risks: Our study did not include measures to evaluate either the job demands (e.g., workload and need to publish), or the psychological risks (e.g., task complexity and conflict within the work group) $\mathrm{PhD}$ students need to face on a daily basis. This is important considering that previous work has suggested both factors as antecedents of burnout in organisational settings (Crawford et al., 2010; Schaufeli \& Bakker, 2004a).

f. Measuring Levels: The study mixes participants from different organisational settings (at the level of university, faculty, and knowledge field). The latter means the results described above might not be entirely accurate because we kept these different levels of analysis as a constant. In addition, despite Smith and collaborators' (1983) suggestion that OCB might be facilitated because of the interdependence of the tasks members of a group need to carry out (i.e., tasks that need the collaboration with others), we did not differentiate between those students who belong to a research group (where interdependence of task is more likely) and those who not (independence).

\section{Future research should pay attention on:}

a. To avoid mixing participants from different organisational settings, we think future research on $\mathrm{PhD}$ students' well-being should focus its efforts on specific units of analysis (i.e., selecting universities rather than collecting data from diverse institutions). In this way, universities with different values and internal practices might be compared to students' engagement, burnout, and OCB. In addition, we also think data from more diverse geographical regions (e.g., Asia and Latin America) need to be collected for 
this kind of research because of two reasons. First, to test whether those factors that predicted the levels of engagement, burnout, and OCB, in our models have the same importance in different cultural contexts. Second, due to the scarce evidence registered from non WEIRD (Western, Educated, Industrialised, Rich, and Democratic) in relation to the social cure approach (cf. Chang, Jetten, Cruwys, Haslam, \& Praharso, 2017) and the study of OCB (see Organ, 2018 for a review).

b. Establish the ideal organisational conditions in terms of psychosocial risk and resources (e.g., how frequently supervision meetings should take place, or the type of support supervisors and faculty members might provide) under which the presence of burnout can be avoided, and both engagement and OCB can be promoted, keeping in mind their downsides we mentioned above.

c. Carry out longitudinal studies to explore changes in students' engagement with their research project, burnout, and the willingness to perform OCB throughout time.

\section{Acknowledgments}

This study was supported by the University of Sussex Doctoral School. We also want to thank Prof John Drury, Dr. Matt Easterbrook, Paul Roberts, and Laura Chapman for their valuable support during different stages of this project.

\section{Supplementary Material}

The Supplementary Material and datasets for this report can be found online at: 


\section{References}

Alnabulsi, H., \& Drury, J. (2014). Social identification moderates the effect of crowd density on safety at the Hajj. Proceedings of the National Academy of Sciences of the United States of America, 111(25), 1-6. https://doi.org/10.1073/pnas.1404953111

Bothwell, E. (2018, February 8). Work-life balance survey: long hours take their toll on academics. Times Higher Education. Retrieved from https://www.timeshighereducation.com/features/work-life-balance-survey-2018-long-hourstake-their-toll-academics

Bowling, N. A., Khazon, S., Alarcon, G. M., Blackmore, C. E., Bragg, C. B., Hoepf, M. R., Barelka, A., Kennedy, K., Wang Q., \& Li, H. (2017). Building better measures of role ambiguity and role conflict. The validation of new role stressor scales. Work \& Stress, 31(1), 1-23. https://doi.org/10.1080/02678373.2017.1292563

Breaugh, J. A., \& Colihan, J. P. (1994). Measuring facets of job ambiguity: Construct validity evidence. Journal of Applied Psychology, 79(2), 191-202. http://dx.doi.org/10.1037/0021-9010.79.2.191

Crawford, E. R., LePine, J. A., \& Rich, B. L. (2010). Linking job demands and resources to employee engagement and burnout: A theoretical extension and meta-analytic test. Journal of Applied Psychology, 95(5), 834-848. http://dx.doi.org/10.1037/a0019364

Curran, T. M., \& Prottas, D. J. (2017). Role stressors, engagement and work behaviours: a study of higher education professional staff. Journal of Higher Education Policy and Management, 39(6), 642-657. https://doi.org/10.1080/1360080X.2017.1377964

Eatough, E. M., Chang, C., Miloslav, S. A., \& Johnson, R. E. (2011). Relationship of role stressors with organizational citizenship behavior: A meta-analysis. Journal of Applied Psychology, 96(3), 619-632. https://doi.org/10.1037/a0021887

Evans, T. M., Bira, L., Beltran-Gastelum, J., Weiss, L. T., \& Vanderford, N. L. (2018). Evidence for mental health crisis in graduate education. Nature Biotechnology, 36(3), 282-284. https://doi.org/10.1038/nbt.4089

Galdino, M. J., Martins, J. T., Fernandez Lourenço Haddad, M. C., Cruz Robazzi, M. L., \& Birolim, M. M. (2016). Burnout syndrome among master's and doctoral students in nursing. ACTA Paulista de Enfermagem, 29(1), 100-107. http://dx.doi.org/10.1590/1982- 0194201600014

González-Romá, V., Schaufeli, W. B., Bakker, A. B., \& Lloret, S. (2006). Burnout and work engagement: Independent factors or opposite poles? Journal of Vocational Behavior, 68, 165174. http://dx.doi.org/10.1016/j.jvb.2005.01.003 
Halbesleben, J. R. B., Harvey, J., \& Bolino, M. C. (2009). Too engaged? A conservation of resources view of the relationship between work engagement and work interference with family. Journal of Applied Psychology, 94(6), 1452-1465. http://dx.doi.org/10.1037/a0017595

Haslam, C., Jetten, J., Cruwys, T., Dingle, G., \& Haslam, S. A. (2018). The New Psychology of Health: Unlocking the Social Cure. New York, NY, US: Routledge.

Haslam, S. A. (2004). Psychology in Organizations (2nd ed.). London, England: SAGE Publications.

Haslam, S. A., O’ Brien, A., Jetten, J., Vormedal, K., \& Penna, S. (2005). Taking the strain: Social identity, social support, and the experience of stress. British Journal of Social Psychology, 44, 355-370. http://dx.doi.org/10.1348/014466605X37468

Haslam, S. A., \& Reicher. S. D. (2006). Stressing the group: Social identity and the unfolding dynamics of response to stress. Journal of Applied Psychology, 91(5), 1037-1052. http://dx.doi.org/10.1037/0021-9010.91.5.1037

Haslam, S. A., Reicher, S. D., \& Levine, M. (2012). When other people are heaven, when other people are hell: How social identity determines the nature and impact of social support. In J. Jetten, C. Haslam, \& S. A. Haslam (Eds.), The social cure: Identity, health and well-being (pp. 157-174). New York, NY, US: Psychology Press.

Higher Education Statistics Agency (HESA). (2018, January). HE student enrolment by level of study 2012/2013 to 2016-2017. Retrieved from https://www.hesa.ac.uk/data-andanalysis/sfr247/figure-3

Illies R., Nahrgang, J. D., \& Morgeson, F. P. (2007). Leader exchange and citizenship behaviors: A meta-analysis. Journal of Applied Psychology, 92(1), 269-277. http://dx.doi.org/10.1037/00219010.92.1.269

Lam, C. F., Wan, W. H., \& Roussin, C. J. (2016). Going the extra mile and feeling energized: An enrichment perspective of organizational citizenship behaviors. Journal of Applied Psychology, 10(3), 379-391. http://dx.doi.org/ 10.1037/apl0000071

Lee, SH., Shin, Y., \& Baek, S. I. (2017). Task characteristics and work engagement: Exploring effects of role ambiguity and ICT presenteeism. Sustainability, 9(10), 1-13. http://dx.doi.org/ 10.3390/su9101855

Levecque, K., Anseel, F., De Beuckelaer, A., Van der Heyden, J., \& Gisle., L. (2017). Work organization and mental health problems in PhD students. Research Policy, 46(4), 868-879. http://dx.doi.org/10.1016/j.respol.2017.02.008 
Lin, SH., Scott, B. A., \& Matta, F. (2018). The dark side of transformational leader behaviors for leader themselves: A conservation of resources perspective. The Academy of Management Journal. Advanced online publication. https://doi.org/10.5465/amj.2016.1255

Macey, W. H., \& Schneider, B. (2008). The meaning of employee engagement. Industrial and Organizational Psychology, 1, 3-30. http://dx.doi.org/10.1111/j.1754-9434.2007.0002.x

Mañas, M. A., Díaz-Fúnez, P., Pecino, V., López-Liria, R., Padilla, D., \& Aguilar-Parra, J. M. (2018). Consequences of team job demands: Role ambiguity climate, affective engagement, and extrarole performance. Frontiers in Psychology, 8, 1-8. https://doi.org/10.3389/fpsyg.2017.02292

Maslach, C. (2003). Job burnout: New directions in research and intervention. Currents Directions in Psychological Science, 12(5), 189-192. https://doi.org/10.1111/1467-8721.01258

Maslach, C., \& Leiter, M. P. (2008). Early predictors of job burnout and engagement. Journal of Applied Psychology, 93(3), 498-512. http://dx.doi.org/10.1037/0021-9010.93.3.498

Maslach, C., \& Schaufeli, W. B. (1993). Historical and conceptual development of burnout. In W. B. Schaufeli, C. Maslach, \& T. Marek (Eds.), Professional Burnout: Recent Developments in Theory and Research (pp. 1-16). London, UK: Routledge.

Norris, F. \& Kaniasty, K. (1996). Received and perceived social support in times of stress: a test of the social support deterioration deterrence model. Journal of personality and social psychology. 71(3), 498-511. http://dx.doi.org/10.1037/0022-3514.71.3.498

Ntontis, E. (2018). Group processes in community responses to flooding: implications for resilience and wellbeing (Unpublished doctoral dissertation). University of Sussex, UK.

Olivares- Faúndez, V. E., Gil-Monte, P. R., Mena, L., Jélvez-Wilke, C., \& Figueiredo-Ferraz, H. (2014). Relationships between burnout and role ambiguity, role conflict and employee absenteeism between health workers. Terapia Psicológica, 32(2), 111-120. http://dx.doi.org/10.4067/S0718-48082014000200004

Organ, D. W. (2018). Organizational citizenship behaviour: Recent trends and developments. Annual Review of Organizational Psychology and Organizational Behavior, 80(1), 295306. https://doi.org/10.1146/annurev-orgpsych-032117-104536

Peltonen, J., Vekkaila, J., Rautio, P., Haverinen, K., \& Pyhältö, K. (2017). Doctoral students’ social sup- port profiles and their relationship to burnout, drop-out intentions, and time to candidacy. International Journal of Doctoral Studies, 12, 157-173. Retrieved from http://www.informingscience.org/Publications/3792 
Postmes, T., Haslam, S. A., \& Jans, L. (2013). A single-item measure of social identification: reliability, validity, and utility. British Journal of Social Psychology, 52(4), 597-617. https://doi.org/10.1111/bjso.12006

Pucheu, A. (in press). ¿Qué influye más? El impacto de liderazgo, cohesión y claridad de rol sobre motivación y burnout, en dos hospitales. Revista Médica de Chile.

Rigg, J., Day, J., \& Adler, H. (2013). Emotional exhaustion in graduate students: The role of engagement, self-efficacy and social support. Journal of Educational and Developmental Psychology, 3(2), 138-152. http://dx.doi.org/10.5539/jedp.v3n2p138

Schaufeli, W. B., \& Bakker, A. B. (2004a). Job demands, job resources, and their relationship with burnout and engagement: A multi-sample study. Journal of Organizational Behavior, 25, 293315. http://dx.doi.org/10.1002/job.248

Schaufeli, W. B., \& Bakker, A. B. (2004b). UWES: Utrecht Work Engagement Scale. Preliminary manual. $\quad$ Retrieved from https://www.wilmarschaufeli.nl/publications/Schaufeli/Test\%20Manuals/Test_manual_UWE S_English.pdf

Schaufeli, W. B., \& Buunk, B. P. (2004). Burnout: An overview of 25 years of research and theorizing. In M. J. Schabracq, J. A. M. Winnubst, \& C. L. Cooper (Eds.), The Handbook of Work and Health Psychology(2nd ed.). Chichester, England: John Wiley \& Sons.

Schaufeli, W. B., Shimazu, A., Hakanen, J., Salanova, M., \& De Witte, H. (2017). An ultra-short measure for work engagement: The UWES-3 validation across five countries. European Journal of Psychological Assessment. Advance online publication. http://dx.doi.org/10.1027/1015-5759/a000430

Sijbom, R. B. L., Lang, J. W. B., \& Anseel, F. (2018). Leaders' achievement goals predict employee burnout above and beyond employees' own achievement goals. Journal of Personality. Advanced online publication. http://dx.doi.org/10.1111/jopy.12427

Smith, C. A., Organ, D. W., \& Near, J. P. (1983). Organizational citizenship behavior: Its nature and antecedents. Journal of Applied Psychology, 68(4), 653-663. http://dx.doi.org/10.1037/00219010.68.4.653

Steffens, N. K., Yang, J., Jetten, J., Haslam, S. A., \& Lipponen, J. (2018). The unfolding impact of leader identity entrepreneurship on burnout, work engagement, and turnover intentions. Journal of Occupational Health Psychology, 23(3), 373-387. http://dx.doi.org/10.1037/ocp0000090 
Stubb, J., Pyhältö, K., \& Lonka, K. (2011). Balancing between inspiration and exhaustion: PhD students' experienced socio-psychological well-being. Studies in Continuing Education, 33(1), 33-50. http://dx.doi.org/10.1080/0158037X.2010.515572

Tunc, T., \& Ozen Kutanis, R. (2009). Role conflict, role ambiguity, and burnout in nurses and physicians at a university hospital in Turkey. Nursey and Health Sciences, 11, 410-416. https://doi.org/10.1111/j.1442-2018.2009.00475.x

University and College Union (UCU). (2016). UCU Workload Survey 2016: Executive summary. Retrieved from https://www.ucu.org.uk/media/8196/Executive-summary---Workload-is-aneducation-issue-UCU-workload-survey-report2016/pdf/ucu_workloadsurvey_summary_jun16.pdf

van Dick, R., Lemoine, J. E., Steffens, N. K., Kerschreiter, R., Akfirat, S. A., Avanzi, L., ... Haslam, S. A. (2018). Identity leadership going global: Validation of the Identity Leadership Inventory across 20 countries. Journal of Occupational and Organizational Psychology, 91, 697728. http://dx.doi.org/10.1111/joop.12223

Van Dyne, L., Graham, J. H., \& Dienesch, R. M. (1994). Organizational citizenship behavior: construct redefinition, measurement, and validation. The Academy of Management Journal, 37(4), 765802. http://dx.doi.org/10.2307/256600

Woolston, C. (2017). Graduate survey: A love-hurt relationship. Nature, 550, 549-552. http://dx.doi.org/10.1038/nj7677-549a

Young. H. R., Glerum, D. R., Wang W., \& Joseph, D. L. (2018). Who are the most engaged at work? A meta- analysis of personality and employee engagement. Journal of Organizational Behavior. Advanced online publication. http://dx.doi.org/10.1002/job.2303 